\title{
ENHANCING THE PERFORMANCES OF ECR ION SOURCES*
}

\author{
G. D. Alton, Y. Liu \\ Physics Division, ORNL, Oak Ridge, TN
}

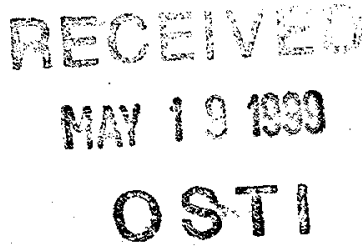

\begin{abstract}
The performances of ECR ion sources can be enhanced in the spatial domain by tailoring the central magnetic field so that it is uniformly distributed over a large plasma volume and is of magnitude so as to be in resonance with single frequency microwave radiation. Analogously, the performances of conventional minimum- $B$ ECR ion sources can be enhanced in the frequency domain by injecting multiple discrete frequency or broadband microwave radiation into their plasma volumes. In this report, examples of both the spatial-and frequency-domain techniques will be given. For example, the design aspects of an all permanent-magnet "volume-type" (spatialdomain) ECR ion source will be described and the effects of injecting multiple frequencies (frequency-domain) on the charge-state-distributions extracted from a conventional minimum- $B$ ECR ion source will be presented.
\end{abstract}

\section{INTRODUCTION}

Electron-cyclotron-resonance (ECR) ion sources are being widely used for the production of highly charged ion beams for heavy ion accelerator based fundamental and applied research. In recent years, considerable progress has been made in ECR ion source technology in terms of their capabilities for generating high-charge-state ion beams as well as total beam intensities. In conventional minimum- $B$ ECR ion sources, narrow bandwidth, single frequency microwave radiation produces thin annular, ellipsoidal-shaped ECR surfaces which constitute a small percentage of the plasma volume and consequently, the efficiency of $R F$ power coupling is limited by the sizes of their ECR surfaces. It has been suggested that the performances of ECR ion sources can be significantly improved by tailoring the central region of the magnetic field so that it is resonant with single frequency microwave radiation (spatial-domain) [1-3] or by injecting multiple-discrete or broadband microwave radiation into conventional minimum- $B$ ECR ion sources (frequencydomain) $[3,4]$.

The spatial-domain technique employs a magnetic field configuration with an extended central flat region, tuned to be in resonance with single-frequency microwave radiation. Because of the large resonant plasma volume, significantly more $R F$ power can be coupled into the plasma, resulting in heating of electrons over a much larger volume than possible in conventional ECR ion sources. The ability to ionize a larger fraction of the

\footnotetext{
- Research supported by the U.S. Department of Energy under contract DE-AC05-OR22464 with the U.S. Department of Energy.
}

particles in the plasma volume effectively reduces the probability of resonant and non-resonant charge exchange, thereby increasing the residence time of an ion in a given charge state and for subsequent and further ionization. All other parameters being equal, the "volume" ECR source should result in higher charge-state distributions, higher beam intensities, and improved operational stability [1-3]. This concept has been recently validated by Heinen, et al., who used the technique to improve the charge states for $\mathrm{Ar}^{q^{+}}(\mathrm{q}>5)$ by factors of 20 to 100 over those from a conventional minimum- $B$ ECR ion source [5] and through the record proton intensities generated with the "flat" field source by Wills, et al. [6]. We are presently fabricating a compact, all-permanent-magnet "volumetype" ECR ion source that incorporates the flat-field concept for high charge-state ion beam generation.

With multiple discrete frequency microwave radiation simultaneously launched into a minimum- $B$ ECR ion source; one can generate multiple, separated and nested ECR heating surfaces. These techniques have been validated at LBNL by increasing the high charge-state population and intensitjes within a particular charge state of $\mathrm{Bi}$ and $\mathrm{U}$ by injecting two frequencies into their AECR source [7] and at ORNL by increasing the charge states and intensities within a particular charge state for $\mathrm{Ar}^{\mathrm{q}^{+}}$and $\mathrm{Xe}^{\mathrm{q}+}$ by injecting three frequencies [8] into the ORNL Caprice ECR /ion source [9].

The design details of an all permanent-magnet "volume-type" ECR ion source for multiply charged ion beam generation and the results derived from the three multi-frequency plasma heating experiments will be described in this report.

\section{DESIGN FEATURES OF AN ALL- PERMANENT MAGNET VOLUME ECR ION SOURCE}

A compact, all-permanent magnet, single-frequency ECR ion based on a novel magnetic field configuration has been designed and is presently under construction [10]. The source is designed to achieve a large, on-axis ECR "volume," which allows ECR power to be efficiently coupled along and about the axis of symmetry. A schematic representation of the source is illustrated in Fig. 1 and the axial magnetic field is displayed in Fig. 2. . As noted, the axial magnetic field profile is flat (constant mod-B) in the center which extends over the length of the central field region along the axis of symmetry and radially outward to form a uniformly distributed ECR plasma "volume". This magnetic field design strongly
"The submitted manuscript has been authored by a contractor of the U.S. Government under contract No. Government retains a nonex the U.S. royalty-free license to publish or reproduce the published form of this contribution, or allow others to do so, for U.S. Govemment purposes." 


\section{DISCLAIMER}

This report was prepared as an account of work sponsored by an agency of the United States Government. Neither the United States Government nor any agency thereof, nor any of their employees, make any warranty, express or implied, or assumes any legal liability or responsibility for the accuracy, completeness, or usefulness of any information, apparatus, product, or process disclosed, or represents that its use would not infringe privately owned rights. Reference herein to any specific commercial product, process, or service by trade name, trademark, manufacturer, or otherwise does not necessarily constitute or imply its endorsement, recommendation, or favoring by the United States Government or any agency thereof. The views and opinions of authors expressed herein do not necessarily state or reflect those of the United States Government or any agency thereof. 


\section{DISCLAIMER}

Portions of this document may be illegible in electronic image products. Images are produced from the best available original document. 
contrasts with those used in conventional ECR ion sources where the central field regions are approximately parabolic and the consequent ECR zones are "surfaces". According to computational studies [1] the new configuration will result in dramatic increases in the absorption of $R F$ power, thus enabling the heating of electrons over a much larger volume, thereby increasing the electron temperature and "hot" electron population in the plasma. The axial mirror field is produced by two, 50mm thick, annular $\mathrm{NdFeB}$ permanent magnets radially magnetized in opposite directions and separated by $\sim 150$ $\mathrm{mm}$. Specially designed and positioned iron cylinders are used to create the flat central field region between the mirror magnets. The source is designed to operate at a central frequency of $\sim 6 \mathrm{GHz}$ and the flat magnetic field region can be adjusted by mechanical means to tune the source to the resonance condition within the limits of 5.6 to $6.9 \mathrm{GHz}$. The plasma confinement magnetic field mirror has a ratio $B_{\operatorname{mad}} B_{E C R}$ of slightly greater than two.

Since the radial magnetic field distribution is proportional to $B=B_{0} r^{N / 2-1}$ where $N$ is the number of cusps and $r$ is the radial distance from the center of the device to the tip of the magnet, a high-order multicusp field for confining the plasma in the radial direction can increase the resonant volume in the radial direction. Therefore, instead of a sextupole field, commonly used in conventional minimum- $B$ ECR ion sources, a 12-pole multicusp field was designed for the source. Twelve $\mathrm{NdFeB}$ bar magnets, equally spaced in an alternating polarity arrangement around the circumference of a 57.2$\mathrm{mm}$ diameter, water cooled $\mathrm{Cu}$ magnet holder, are used to produce the desired field for radial confinement, as shown in Fig. 3. In combination with the axial mirror field, a magnetic field strength of $5.1 \mathrm{kG}$, approximately equal to that of the axial mirror field, is generated at the inner wall of the plasma chamber. For comparison, the radial field profile for a sextupole configuration $(N=6)$ is also plotted in Fig. 3. As noted, the region over which the field region is uniform is much greater for the $N=12$ multicusp field.

The cylindrical cavity plasma chamber is made of $\mathrm{Al}$ and is $15.6 \mathrm{~cm}$ in length and $5.4 \mathrm{~cm}$ in diameter. Computational design studies were performed for several different $R F$ injection schemes, using the finite element code ANSYS [11]. A broadband $R F$ injection system was then designed for the ion source. It is a long, precisely

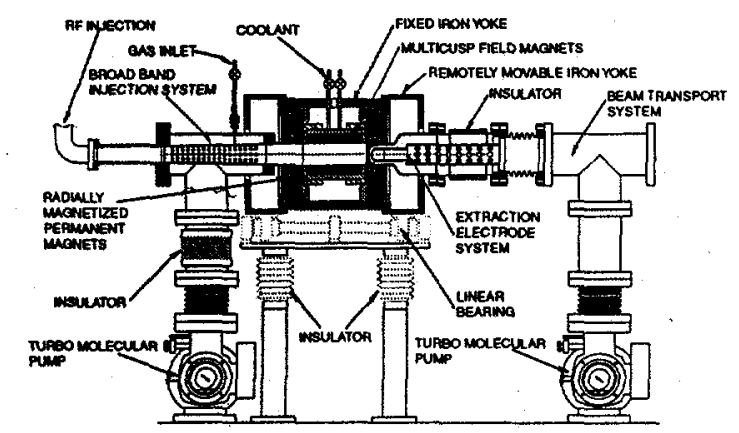

Fig. 1. Schematic view of the flat- $B$ ECR ion source.

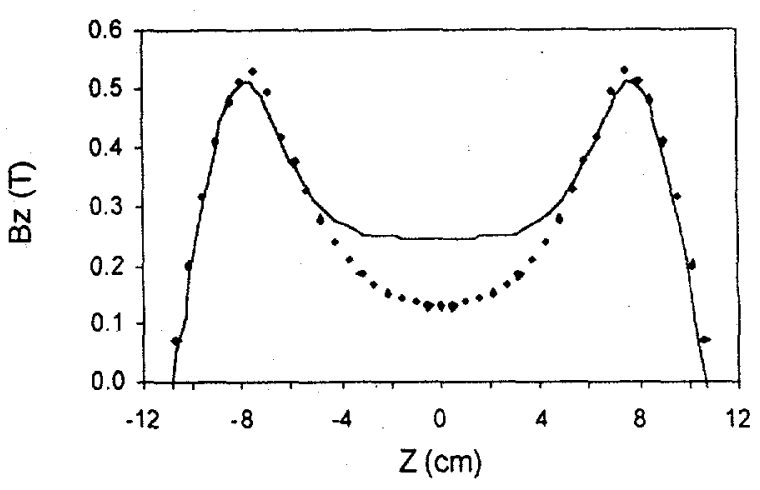

Fig. 2. Axial magnetic field profiles of the volume" (solid line) and conventional minimum- $B$ configuration on "surface" (dotted line) ECR ion sources.

tapered rectangular-to-circular transition section, starting from a rectangular WR 137 waveguide and ending with a circular diameter that matches the dimension of the plasma chamber. The transition from rectangular to circular is very smooth so that it has excellent voltage standing wave ratio (VSWR) while converting the rectangular waveguide $T E_{10}$ dominant mode to the dominant circular waveguide $T E_{\operatorname{lnp}}$ eigenmodes with the $R F$ power concentrated near the axis of the resonant plasma volume and the $E$-vector oriented perpendicular to the magnetic field direction for efficient electron heating. The mechanical design of the source is very flexible in that it can be converted from a "volume" source to a "surface" source and vice-versa by simply adding/removing a $\mathrm{Fe}$ ring to/from the central region between the mirror magnets. The resulting minimum- $B$ axial magnetic field profile, after adding the $\mathrm{Fe}$ ring, is also shown in Fig. 2. The multicusp field can also be changed to an $N=6$ field distribution when the source is

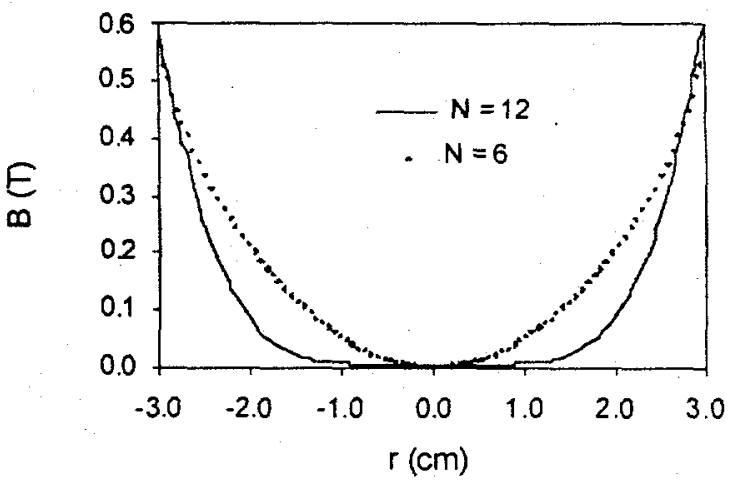

Fig. 3. Comparison of $N=6$ and $N=12$ cusp radial magnetic field profiles. The effect of increasing the number of cusps from $N=6$ to $N=12$ is apparent: the lower order multiple field results in a much smaller resonant plasma volume. 
configured as a conventional "surface" source. Comparisons will be made of the performances of the "volume" and conventional single-frequency "surface" ECR sources in terms of the charge-state distributions and intensities within a particular charge-state for each configuration.

\section{MULTI-FREQUENCY MICROWAVE PLASMA HEATING}

We have conducted comparative studies to assess the relative performance of the conventional minimum- $B$ ORNL Caprice ECR ion source [9] for the production of multiply charged ion beams when excited with one, two and three-frequency microwave radiation [8]. In order to simultaneously inject three frequencies into the plasma chamber of the source, it was found necessary to design and fabricate an appropriate waveguide/injection system to avoid cross coupling of the radiation in the waveguide system. The ORNL Caprice source, equipped with the new three-frequency injection module, is shown in Fig. 4. Microwave radiation between 10 and $14 \mathrm{GHz}$ can be injected into the source. The studies were conducted with the existing $10.6 \mathrm{GHz}, 1 \mathrm{~kW}$, klystron power supply and two TWT-based microwave power supplies with rated powers of 80 and $200 \mathrm{~W}$, respectively.

One, two and three-frequency heating experiments were conducted with Xe feed gas with $10.6 \mathrm{GHz}(290 \mathrm{~W})$, $10.6 \mathrm{GHz}(290 \mathrm{~W})+11.57 \mathrm{GHz}(40 \mathrm{~W})$ and $10.6 \mathrm{GHz}$ $(290 \mathrm{~W})+11.57 \mathrm{GHz}(40 \mathrm{~W})+12 \mathrm{GHz}(52 \mathrm{~W})$ microwave power. Fig. 5 shows the resulting charge-state distributions derived from these studies. It is clear that, with the addition of the second and third frequencies, the most probable $\mathrm{Xe}^{q^{+}}$charge state moves to higher values by one unit and the intensities for the high-charge states are increased by $\sim 3$ over those for the saturated, singlefrequency $10.6 \mathrm{GHz}(290 \mathrm{~W})$ case. Our results clearly illustrate that the performance of conventional geometry ECR ion sources can be significantly improved by use of multiple-discrete frequency plasma heating.

\section{REFERENCES}

1. G. D. Alton, and D. N. Smithe, Rev. Sci. Instrum. 65 (1994) 775.

2. G. D. Alton, and D. N. Smithe, Physica Scripta T71 (1996) 66.

3. G. D. Alton, Proc. of the 14th Int. Conference on Cyclotrons and their Applications, ed. J. C. Cornell (Capetown, South Africa, October 8-13, 1995), World Scientific, Singapore, p. 362.

4. G. D. Alton, Nucl. Instr. and Meth. A 382 (1996) 276.

5. A. Heinen, et al., Rev. Sci. Instrum. 69 (1998) 729.

6. J. S. C. Wills, R. A. Lewis, J. Diserens, H. Schmeing, and T. Taylor, Rev. Sci. Instrum. 69 (1998) 65.

7. Z. Q. Xie, and C. M. Lyneis, in Proc. of the 12th Int. Workshop on ECR Ion Sources (Wakoshi, Japan, April 25-27, 1995), eds. M. Sekiguchi and T. Nakagawa, INS-J-182 (1995) 24.

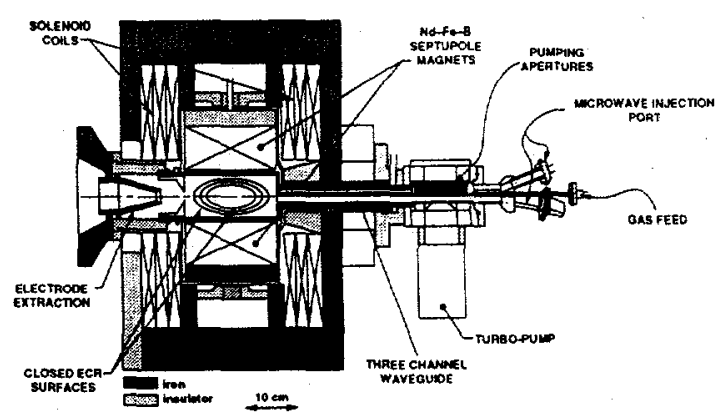

Fig. 4. Schematic drawing of the ORNL Caprice ECR ion source [9] equipped with a three-frequency microwave injection system.

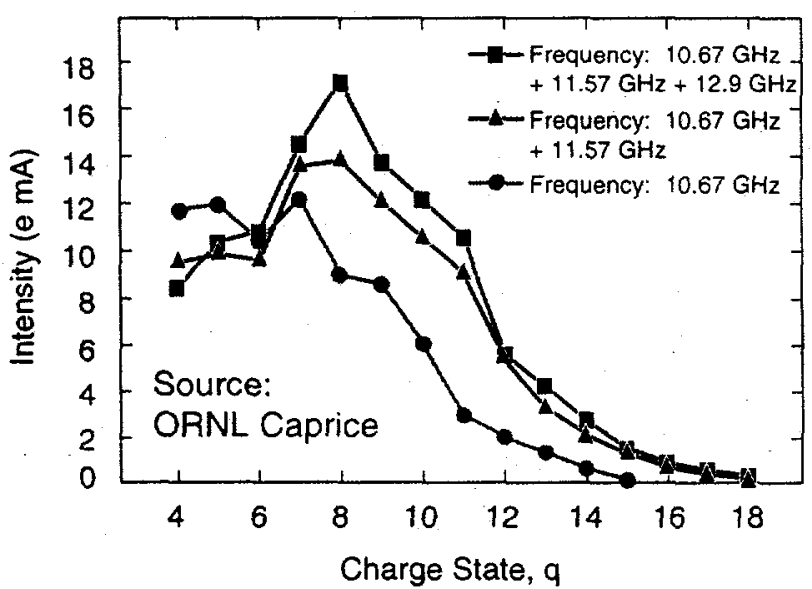

Fig. 5. Charge-state distributions for $\mathrm{Xe}$ ion beams extracted from the ORNL Caprice ECR ion source [9] equipped with a three-frequency microwave injection system; lower curve: $290 \mathrm{~W}$ of $10.6 \mathrm{GHz}$ klystron power (optimized); middle curve: $290 \mathrm{~W}$ of $10.6 \mathrm{GHz}$ klystron power (optimized) and $40 \mathrm{~W}$ of $11.59 \mathrm{GHz}$ TWT power (nonoptimized); and upper curve: combination of $290 \mathrm{~W}$ of $10.6 \mathrm{GHz}$ klystron power (optimized), $40 \mathrm{~W}$ of 11.57 GHz TWT power (nonoptimized), and $52 \mathrm{~W}$ of 12.9 $\mathrm{GHz}$ TWT power (nonoptimized) [8].

8. G. D. Alton, F. W. Meyer, Y. Liu, J. R. Beene, and D. Tucker, Rev. Sci. Instrum. 69 (1998) 2305.

9. F. W. Meyer, M. E. Bannister, C. C. Havener, O. Woitke, and $Q$. Yan, in Proceedings of the Thirteenth International Workshop on ECR Ion Sources, edited by D. May. Texas A\&M University, February, 1997, p. 102.

10. Y. Liu, G. D. Alton, G. D. Mills, C. A. Reed, and D. L. Haynes, Rev. Sci. Instrum. 69 (1998) 1311

11. ANSY is a finite element code marketed by ANSYS, Inc.. Cannonsburg, PA 15317, USA 